\title{
Retraction Note: The loss rate of coastal soil based on abnormal track detection and the development of agricultural tourism economy
}

\author{
Xiuchun Lin ${ }^{1}$
}

Published online: 6 December 2021

C) Saudi Society for Geosciences 2021

Retraction Note: Arabian Journal of Geosciences (2021) 14: 1749 https://doi.org/10.1007/s12517-021-08082-3

The Editor-in-Chief and the Publisher have retracted this article because the content of this article is nonsensical. The peer review process was not carried out in accordance with the Publisher's peer review policy. The author has not responded to correspondence regarding this retraction.

Xiuchun Lin

riluozahuopu@163.com

1 China Agricultural University, Beijing 100083, China 